\title{
Cholesterol-lowering phytosterols: factors affecting their use and efficacy
}

This article was published in the following Dove Press journal:

Nutrition and Dietary Supplements

29 July 2010

Number of times this article has been viewed

\section{Timothy P Carr \\ Mark M Ash \\ Andrew W Brown}

Department of Nutrition and Health Sciences, University of Nebraska, Lincoln, NE, USA
Correspondence:Timothy P Carr Department of Nutrition and Health Sciences, University of Nebraska,

316 Leverton Hall, Lincoln,

NE 68583-0806, USA

Email tcarr2@unl.edu

\begin{abstract}
Phytosterols are essential components of plant cells and therefore naturally present in the human diet. When used therapeutically, phytosterols can significantly lower serum cholesterol concentrations. Meta-analyses of clinical trials indicate about 10\% reduction of low-density lipoprotein cholesterol when phytosterols are consumed at the recommended dose of $2 \mathrm{~g} / \mathrm{d}$. Thus, phytosterols can be an important part of an overall dietary strategy to manage cholesterol levels, particularly for patients who cannot tolerate cholesterol-lowering drugs. Although other health benefits have been attributed to phytosterols, including anti-inflammatory, anticancer, and immune regulatory effects, this review will focus on the therapeutic use of phytosterols related to serum cholesterol, their mechanisms of action, and the various types of phytosterols available to consumers.
\end{abstract}

Keywords: sterols, stanols phytosterols, cholesterol

\section{Natural phytosterol intake}

Plant oils, legumes, nuts, and seeds have relatively high concentrations of phytosterols, whereas cereal grains, fruits, and vegetables contain only modest amounts of phytosterols. ${ }^{1-5}$ However, because of the high intake of cereal products in humans, cereals are quantitatively an important source of phytosterols. ${ }^{6,7}$ Total intake of phytosterols from natural sources is estimated to be $200-300 \mathrm{mg} / \mathrm{d}$ in various populations and is similar to daily cholesterol intake, whereas Asian and vegetarian diets provide at least double the amount of phytosterols. ${ }^{8}$

Some evidence suggests that phytosterols consumed in normal habitual dietary quantities can influence cholesterol metabolism. Ostlund and coworkers ${ }^{9,10}$ demonstrated that phytosterols naturally present in wheat germ and corn oil significantly decreased intestinal cholesterol absorption. Although serum cholesterol levels were not reported, a direct association is known to exist between cholesterol absorption and serum cholesterol concentration. ${ }^{11-15}$ In addition, the amount of phytosterols consumed in habitual diets was reported to be inversely correlated with serum cholesterol concentration. ${ }^{16,17}$ It has also been suggested that the cholesterol lowering properties of many edible oils may be attributed, at least in part, to their phytosterol content. ${ }^{18}$ Taken together, these findings suggest that intake of phytosterols at levels found naturally in the food supply may exert a minimal cholesterol-lowering effect, but that supplemental doses of phytosterols are required to achieve maximal reductions in serum cholesterol.

\section{Types of phytosterols}

The term "phytosterols" is used widely to include the various plant-derived sterols and stanols, in free or conjugated form, that are present in food as naturally-occurring 
compounds or as added ingredients. Chemically speaking, this includes 4-desmethyl sterols and stanols containing a C-3 hydroxyl group (Figure 1). Although cholesterol is not a phytosterol, it shares structural similarities with common dietary phytosterols. Phytosterols and cholesterol function similarly in plant and animal cells, respectively, by providing structural integrity to cell membranes; however, phytosterols are not synthesized by animals and enter the body only via the diet. The main structural difference between cholesterol and plant sterols is in the side chain, where plant sterols have an additional methyl group (campesterol), ethyl group (sitosterol), or double bond (stigmasterol). When the sterols are fully saturated, the corresponding molecules are campestanol and sitostanol/stigmastanol (Figure 1). The terms<smiles>CC(C)CCCC(C)C1CCC2C3CC=C4CC(O)CC[C@]4(C)C3CC[C@]12C</smiles>

A. Cholesterol<smiles>CC(CC[C@@H](C)C(C)C)C1CCC2C3CC=C4C[C@@H](O)CC[C@]4(C)C3CC[C@]12C</smiles>

B. Campesterol<smiles>CC[C@H](CCC(C)C1CCC2C3CC=C4C[C@@H](O)CC[C@]4(C)C3CC[C@]12C)C(C)C</smiles>

C. Sitosterol<smiles>CCC(/C=C/C(C)C1CCC2C3CC=C4C[C@@H](O)CC[C@]4(C)C3CC[C@]12C)C(C)C</smiles>

D. Stigmasterol<smiles>CC(C)C(C)CCC(C)C1CCC2C3CCC4CC(O)CCC4(C)C3CC[C@]12C</smiles>

E. Campestanol<smiles>CC[C@H](CCC(C)C1CCC2C3CCC4CC(O)CC[C@]4(C)C3CC[C@]12C)C(C)C</smiles>

F. Sitostanol (Stigmastanol)

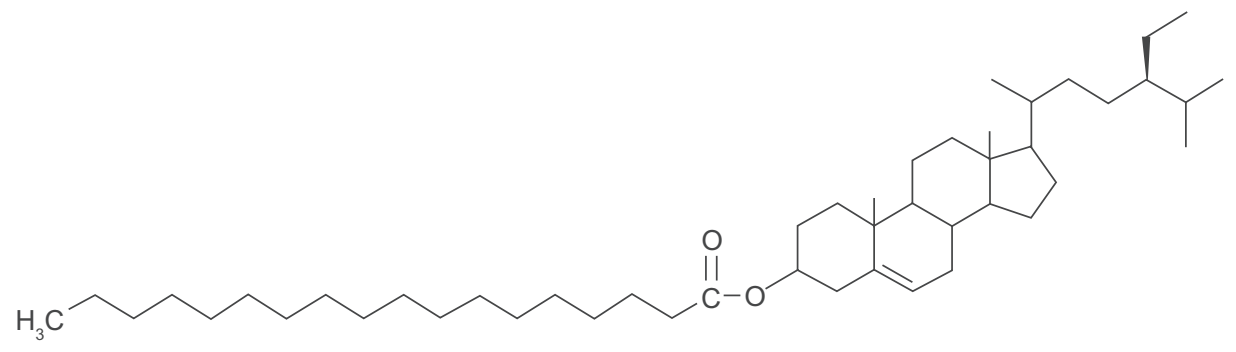

G. Sitosterol ester

Figure I Chemical structure of cholesterol (A), plant sterols (B, C, D), plant stanols (E, F), and plant sterol ester (G). Cholesterol is an animal sterol and consumed only with animal-derived foods. Plant stanols are much less abundant than sterols in the natural state but can be produced commercially by hydrogenation of sterols. Esters of sterols and stanols are also produced commercially to enhance their solubility in food products. 
sitostanol and stigmastanol refer to the same molecule, although the name "sitostanol" seems to be the most frequent choice. Saturated stanols comprise about $5 \%-10 \%$ of total phytosterols naturally present in the human $\operatorname{diet}^{8}$

Phytosterols may exist as free alcohols or as conjugated forms, including glycosides and esters of fatty acids or ferulic acid. Phytosterols in oilseeds are found mainly as free sterols and fatty acid esters, ${ }^{19}$ whereas a significant proportion of phytosterols from cereals are found as steryl glycosides and ferulates. $^{20}$

Phytosterols used as added ingredients are obtained commercially from two main sources: pine tall oil and vegetable oils. Tall oil, also called liquid rosin, is a byproduct of the wood pulping industry. The viscous liquid contains resins, fatty acids, and phytosterols; the phytosterols are recovered by distillation. Tall oil sterols contain a high proportion of sitosterol (up to $80 \%$ ), with the remainder being campesterol and saturated stanols. ${ }^{21}$ Vegetable oil phytosterols are recovered as by-products during the refining of soybean, rapeseed (canola), and other edible oils. ${ }^{22}$ The small amount of steryl glycosides present in vegetable oils is lost during the initial degumming step. The oils are then treated with alkali (to remove unwanted free fatty acids) and passed through activated clay (to remove unwanted colored substances), which may cause further losses of phytosterols. The final deodorization step is achieved by steam distillation, which removes a significant amount of free sterols but leaves behind steryl fatty acid esters. In the case of soybean oil distillates, the phytosterol composition is approximately 55\% sitosterol, 20\% campesterol, 18\% stigmasterol, and a relatively low amount of saturated stanols. ${ }^{22,23}$ Phytosterol composition from either tall oil or vegetable oils will vary depending on species and variety, growing location and season, and the extent of processing. ${ }^{21,23}$

In commercial production, sterols may be hydrogenated to yield stanols. Hydrogenation of tall oil phytosterols results in $>90 \%$ sitostanol and small amounts of campestanol, whereas hydrogenation of soybean or rapeseed oil phytosterols results in approximately $70 \%$ sitostanol and $30 \%$ campestanol. Free sterols or stanols may also be esterified with fatty acids from edible oils, resulting in significantly greater solubility in oil-based foods such as margarine. ${ }^{8}$ Furthermore, for the application of sterols and stanols in beverages and in other high-moisture foods, they (or their esters) should be attached to carriers or dissolved in emulsions to create water-dispersible forms. Because of increasing demand for phytosterol-enriched foods, most of the major ingredient companies sell products comprising free sterols or stanols (or mixtures thereof), fatty acid esters of sterols or stanols, and water-dispersible free or esterified sterols/stanols.

\section{Management issues in treating dyslipidemia}

Cardiovascular diseases (CVD) include any disorder of the heart or blood vessels and, collectively, are the leading causes of death worldwide, claiming an estimated 17.1 million lives in 2004 and accounting for $29 \%$ of all global deaths. ${ }^{24}$ In the most recent years for which data are available, CVD caused $33 \%$ of all deaths in the United States ${ }^{25}$ and $48 \%$ of all deaths in Europe. ${ }^{26}$ The majority of CVD deaths are attributed to stroke and coronary heart disease (CHD), clinical disorders that share a common pathology characterized by atherosclerotic plaque formation within the arteries. Several risk factors are known to contribute to plaque formation, including physical inactivity, smoking, and dyslipidemia. ${ }^{27}$ The US National Cholesterol Education Program defines dyslipidemia as serum triglyceride $>150 \mathrm{mg} / \mathrm{dL}(1.7 \mathrm{mmol} / \mathrm{L})$, high-density lipoprotein (HDL) cholesterol $<40 \mathrm{mg} / \mathrm{dL}(1.0 \mathrm{mmol} / \mathrm{L})$, and LDL cholesterol $>100 \mathrm{mg} / \mathrm{dL}(2.6 \mathrm{mmol} / \mathrm{L}){ }^{28,29}$

To combat dyslipidemia, patients have several treatment options that include drugs, diet, and lifestyle changes (or combinations thereof). Drugs are effective but produce adverse effects in a significant proportion of patients. Statins are the most widely prescribed lipid-lowering drugs worldwide, but they produce adverse effects in up to $33 \%$ of patients. ${ }^{30-33}$ Adverse effects are also associated with ezetimibe, ${ }^{34}$ fibrates, ${ }^{35}$ and niacin ${ }^{36}$ at rates of up to $18 \%, 23 \%$, and $90 \%$, respectively. Adverse effects may include liver, muscle, and kidney dysfunctions; skin disorders; abdominal pain; nausea; constipation; dizziness; flushing; neurological disorders; and cognitive impairment.

On the other hand, therapies based on dietary and lifestyle changes produce little or no adverse events and are the cornerstone of recommendations by the US National Cholesterol Education Program, ${ }^{29}$ the American Heart Association, ${ }^{37}$ and the World Health Organization. ${ }^{38}$ Recommendations include reduced intake of saturated fat and cholesterol while increasing physical activity and intake of dietary fiber. In addition, the US National Cholesterol Education Program recommends including $2 \mathrm{~g} / \mathrm{d}$ of phytosterols to enhance lowering of LDL cholesterol. ${ }^{29}$ As discussed below, phytosterols may also be used in combination therapy to reduce the dose of coadministered drugs, thus decreasing the risk of drug-related adverse effects.

\section{Mechanisms of action}

Metabolic differences between cholesterol and phytosterols were first reported 80 years ago with the observation that phytosterols are essentially excluded from absorption. ${ }^{39}$ In the years that followed, the proposed mechanisms for 
the cholesterol-lowering properties of phytosterols have centered on metabolic events shared by cholesterol and phytosterols, including intestinal solubility, cellular uptake, gene regulation, and interaction with digestive enzymes.

\section{Intestinal solubility of cholesterol}

Cholesterol in the intestinal lumen comes from both dietary and biliary sources, whereas diet is the only substantial source of phytosterols. ${ }^{8}$ Biliary cholesterol is secreted into the intestine in the form of mixed micelles primarily composed of a mixture of bile salts, phosphatidylcholine, and cholesterol. ${ }^{40}$ Biliary secretions are important for efficient micellarization of dietary sterols, as well as other dietary components. Micellarization of sterols, in turn, results in more efficient absorption, with smaller donor particles resulting in more efficient absorption, ${ }^{41}$ possibly by being able to better penetrate the unstirred water layer at the brush border membrane of the enterocyte.

Nonesterified dietary phytosterols compete with dietary cholesterol for micellarization, as well as displacing micellarized biliary cholesterol. ${ }^{42}$ Because biliary cholesterol secretion contributes a greater amount of cholesterol to the intestinal lumen than the diet, the displacement of biliary cholesterol from micelles is quantitatively more important. The competition of phytosterols with cholesterol for micellarization occurs with free ${ }^{43}$ but not esterified sterols (Carr TP and Brown AW, unpublished data). Thus, the phytosterol esters must be first hydrolyzed to compete for micellarization.

The solubility of cholesterol in micelles depends in part on the hydrophobicity of bile salts. ${ }^{43} \mathrm{~A}$ "hydrophobicity index" is used to determine the overall hydrophobicity of a bile salt mixture, such as that found in the intestine or bile. ${ }^{44}$ Besides simple competition for micellarization, dietary phytosterols have also been shown to decrease the hydrophobicity index of bile salts, ${ }^{11}$ thereby potentially decreasing cholesterol solubilization. How phytosterols alter bile salt compositions is still uncertain, although the presence of phytosterols in the intestinal lumen may affect the microbiota population, thus altering secondary bile acid synthesis. ${ }^{45}$

Another proposed mechanism for decreasing cholesterol solubility in the intestinal lumen is cocrystallization of phytosterol and cholesterol, although the data are rather limited. Although one in vitro study ${ }^{46}$ suggested that cocrystallization may occur, Mel'nikov et $a l^{47}$ concluded that both cholesterol and phytosterols are highly soluble in hydrolysis products of dietary lipids, making cocrystallization unlikely.

\section{Protein-mediated sterol transport}

Cholesterol absorption efficiency in humans is approximately $50 \%$, highly as free sterol. Although there is some evidence that esterified cholesterol can be absorbed via proteinmediated transport, ${ }^{48}$ free sterols are more efficiently absorbed in vivo due to their ability to incorporate into micelles. One of the hallmarks of dietary phytosterols is their ability to lower cholesterol absorption while being poorly absorbed themselves. Phytosterol absorption ranges from $0.04 \%$ for sitostanol and $1.9 \%$ for campesterol in one study ${ }^{49}$ and up to $19 \%$ for campesterol in other study. ${ }^{50}$ The apparent differences in calculated absorption stem from the potential for a saturable absorption mechanism, ${ }^{49}$ as well lower absorption values obtained through blood measurements compared with higher absorption calculated through fecal sterol analysis. Nevertheless, the striking difference in absorption between cholesterol and phytosterols implicates protein-mediated sterol transporters. A number of proteins are believed to be involved in cellular influx, including Niemann-Pick C1 like 1 (NPC1L1), scavenger receptor class B type I (SR-BI), and the fatty acid translocase $\mathrm{CD} 36 ;{ }^{51}$ other proteins are implicated in cellular efflux, including the ATP-binding cassette (ABC) transporters ABCA1, ABCG1, and the ABCG5/G8 heterodimer. ${ }^{52}$

NPC1L1 has been implicated as being essential for cholesterol absorption of higher capacity, with only $15 \%$ cholesterol absorption occurring when NPC1L1 was knocked out. ${ }^{53}$ Although one study indicated that NPC1L1 did not facilitate absorption of phytosterols,${ }^{54}$ another study demonstrated that NPC1L1 facilitated sitosterol uptake at approximately $40 \%$ of the rate compared with cholesterol, ${ }^{55}$ and still others have reported that phytosterol absorption is markedly decreased when NPC1L1 was knocked out in mice. ${ }^{56,57}$ In contrast, SR-BI and CD36 facilitate intestinal uptake of sterols to the membrane but did not affect cholesterol absorption in mice. ${ }^{58}$ These transporters are also present in the liver and perform a similar role of transporting sterols across the biliary canalicular membrane. To date, little work has been done to determine the transport of phytosterols involving these proteins or the direct competition between phytosterols and cholesterol for these transporters.

The transporters ABCA1, ABCG1, and ABCG5/G8 are important for sterol efflux. The hyperabsorption and accumulation of phytosterols, commonly called sitosterolemia, has been attributed to mutations in the sterol efflux heterodimer ABCG5/G8 ${ }^{59}$ The increase in phytosterols in individuals with malfunctioning ABCG5/G8 initially led to the conclusion that ABCG5/G8 was the phytosterol-specific efflux protein but 
later found to also transport cholesterol ${ }^{60} \mathrm{ABCA} 1$ is present in multiple tissues and transports cholesterol to apo AI as part of the process of developing nascent HDL, ${ }^{61}$ whereas ABCG1 transports cholesterol to mature HDL. ${ }^{62}$ However, the $\mathrm{ABC}$ transporters do not appear to selectively transport phytosterols vs cholesterol. ${ }^{63,64}$

The direct regulation of intestinal genes by phytosterols has also been investigated, but to a limited extent. In the human FHs 74 Int small intestine cell line, Jesch et al ${ }^{65}$ reported that sitosterol (but not stigmasterol) reduced the mRNA levels of NPC1L1 and HMG-CoA reductase to the same extent as cholesterol, suggesting that sitosterol had equivalent regulatory properties as cholesterol. In Caco-2 cells, sitosterol upregulated ABCA1 and LXR compared with cholesterol in one study, ${ }^{66}$ but not in another. ${ }^{63}$ In a hamster model, sitostanol supplementation decreased cholesterol absorption but did not alter gene expression of NPC1L1 or ABCG5/G8. ${ }^{67}$ Calpe-Berdiel et al ${ }^{68}$ fed phytosterols to three mouse models (C57BL/6J controls, apoE deficient, and LDL receptor deficient) and found intestinal mRNA levels for NPC1L1, ABCA1, and ABCG5/G8 increased in C57BL/6J mice but decreased in the gene knockout models. In the latter study, the changes in gene expression did not correlate with cholesterol absorption or serum cholesterol concentration. ${ }^{68}$ Taken together, these data suggest that although phytosterols may exert some regulatory effect on gene expression, they primarily inhibit cholesterol absorption by mechanisms other than gene regulation.

\section{Enzymatic interaction}

The interaction of phytosterols with cholesterol-metabolizing enzymes can dramatically affect their ability to impact cholesterol absorption. One such enzyme, pancreatic cholesterol esterase, is involved in hydrolyzing sterol esters into unesterified sterols. Specificity of the enzyme depends on the sterol moiety (with cholesterol esters more rapidly hydrolyzed than phytosterol esters), ${ }^{69}$ the fatty acyl moiety (with saturated esters being less efficiently hydrolyzed than unsaturated), ${ }^{69}$ or dihydroxystearate esters inhibiting the enzyme. ${ }^{70}$ The degree of ester hydrolysis will determine the extent of sterol incorporation into micelles and subsequent absorption. Because a relatively small amount of dietary cholesterol is esterified, ${ }^{8}$ phytosterol esters, when consumed at therapeutic doses, are a more important substrate for pancreatic cholesterol esterase. Therefore, the relative rate of hydrolysis could impact the efficacy of phytosterol esters.

The intracellular enzyme, acyl-CoA:cholesterol acyltransferases (ACAT), converts free sterols to sterol esters, which are the primary forms incorporated into chylomicrons. ACAT isoforms have been shown to have dramatically lower substrate specificity for phytosterols than for cholesterol, ${ }^{71-73}$ resulting in more free phytosterols being available for return to the intestinal lumen (via ABCG5/G8) or removal from macrophages (via ABCA1 and ABCG1). However, this difference in specificity does not appear to be an important mechanism for lowering cholesterol absorption as the presence of sitosterol along with cholesterol did not inhibit cholesterol esterification. ${ }^{71,74}$ Instead, this difference in specificity may be responsible for the low phytosterol accumulation in humans.

\section{Phytosterol efficacy, dose, and dose frequency}

Although phytosterol intake at levels found naturally in food may exert a slight hypocholesterolemic effect, higher doses of phytosterols at therapeutic levels can significantly lower serum LDL cholesterol. Most reports are in agreement that phytosterols lower LDL cholesterol but have little effect on serum triglycerides or HDL cholesterol. ${ }^{75-78}$ Katan et $\mathrm{al}^{75}$ acknowledged that phytosterols lowered serum triglycerides in a few studies but asserted that the effect is sporadic and not supported by the general body of literature. Some studies suggest that phytosterols may decrease serum triglycerides in subjects with high serum concentrations of triglycerides. ${ }^{79,80}$ Nevertheless, the general consensus is that phytosterol therapy is most effective for lowering LDL cholesterol with maximum efficacy at approximately $3 \mathrm{~g} / \mathrm{d} .^{75,76,81}$ Demonty et $\mathrm{l}^{81}$ recently developed a continuous dose-response equation using 141 trial arms (from 84 studies) and concluded that a dose of $3 \mathrm{~g} / \mathrm{d}$ lowers LDL cholesterol $11 \%$, whereas a dose of $2 \mathrm{~g} / \mathrm{d}$ lowers LDL cholesterol $9 \%$. The equation included a dose range of $0.5-9.0 \mathrm{~g} / \mathrm{d}$. Other analyses ${ }^{75,76}$ are consistent in demonstrating maximum efficacy at approximately $3 \mathrm{~g} / \mathrm{d}$, but that $2 \mathrm{~g} / \mathrm{d}$ is nearly as effective and probably represents a more reasonable and achievable dose. Consequently, the US National Cholesterol Education Program recommends a phytosterol dose of $2 \mathrm{~g} / \mathrm{d}$ to enhance lowering of LDL cholesterol. ${ }^{29}$

The impact of dose frequency (and time of dose) has also been examined, but the data are inconclusive. Some studies indicate that a single daily dose of phytosterols (2.5-3.2 g/d) given at breakfast or lunch was sufficient to significantly decrease LDL cholesterol. ${ }^{82-84}$ In contrast, after adjusting for placebo effects, a single dose of 1.7-1.8 g/d did not lower LDL cholesterol. ${ }^{85,86}$ One possible explanation is that the lower doses $(1.7-1.8 \mathrm{~g} / \mathrm{d})$ were not adequate 
to elicit reductions in LDL cholesterol. However, a $1.8 \mathrm{~g} / \mathrm{d}$ dose divided equally at each of three daily meals significantly lowered LDL cholesterol, whereas the same $1.8 \mathrm{~g}$ dose given entirely at breakfast did not. ${ }^{87}$ Meta-analysis of these and other studies suggests that an increase in dose frequency is associated with larger decreases in LDL cholesterol. ${ }^{81}$

\section{Effect of baseline serum cholesterol}

The relationship of baseline serum cholesterol to phytosterol efficacy has been examined in an effort to understand the factors that influence an individual's response to phytosterol therapy. Some studies have reported a significant correlation between baseline LDL cholesterol concentration and the magnitude of change, ${ }^{88,89}$ whereas others have not. ${ }^{90-92}$ Using a systematic approach, Naumann and coworkers ${ }^{79}$ analyzed data from five studies conducted in their laboratory and concluded that phytosterol consumption resulted in larger absolute decreases in LDL cholesterol when patients had higher baseline serum levels, but the percent decrease was not affected. A recent meta-analysis of 141 trial arms also supported the conclusion that absolute (but not relative) changes in LDL cholesterol are significantly correlated with baseline LDL cholesterol concentration, thus indicating that phytosterol therapy in individuals with higher baseline LDL levels have greater absolute reductions in LDL cholesterol. ${ }^{81}$

\section{Food matrix and background diet}

Phytosterols have been incorporated into various food matrices and tested under many different background diets. Although the results have been variable, phytosterols have significantly lowered serum LDL cholesterol when incorporated into margarine spreads, low-fat yogurt drinks, low-fat fermented milk, mayonnaise, salad dressings, chocolate, orange juice, vegetable juice, hard cheese, fresh cheese, milk, tea, ground beef, muffins, croissants, bread, lemonade, vegetable oil, butter, tortilla chips, nonfat beverages, cereals, capsules, and tablets. ${ }^{81}$ The efficacy of phytosterols appears to function independently of dietary fat; thus there has been a movement to incorporate phytosterols into low-fat foods in order to promote a low-fat, low-cholesterol diet profile to further improve healthy lipid profiles. ${ }^{93}$ Despite the variability of phytosterol efficacy in various food matrices, the meta-analysis by Demonty et $\mathrm{al}^{81}$ suggested that neither the fat content nor the nature of the food as dairy or nondairy significantly affected the LDL cholesterol lowering efficacy of the phytosterol product. However, the comparison of solid and liquid foods indicated that phytosterols delivered within solid matrices might be slightly more effective than within liquid foods. ${ }^{81}$
In contrast, a meta-analysis by AbuMweis et $\mathrm{al}^{94}$ concluded that reductions in LDL cholesterol were greater when phytosterols were incorporated into fat spreads, mayonnaise, salad dressing, milk, and yogurt compared with croissants, muffins, orange juice, nonfat beverages, cereal bars, and chocolate. In another study, phytosterols were reported to have significantly different abilities to lower LDL cholesterol when incorporated into different low-fat food matrices: milk (15.9\%) > yogurt $(8.6 \%)>$ bread $(6.5 \%)=$ breakfast cereal $(5.4 \%) .{ }^{95}$ Phytosterol tablets have also been used, demonstrating a decrease in LDL cholesterol of 9.1\%. ${ }^{96}$ However, in a study comparing phytosterol-lecithin tablets and capsules, the tablets led to a decrease in cholesterol, whereas the capsules did not. ${ }^{97}$ Other trials have demonstrated that encapsulated phytosterol esters effectively lowered LDL cholesterol. ${ }^{98-100}$ Taken together, the data suggest that the dietary delivery system could have an impact on the efficacy of phytosterols, although making a general conclusion about specific food matrices may be difficult given that individuals consume a variety of mixed foods on a daily basis that could influence phytosterol efficacy to some degree.

\section{Combination therapies to lower cholesterol}

For individuals who cannot achieve LDL cholesterol target goals with diet and phytosterols alone, certain combination treatments may offer some advantages. We have reviewed the literature on phytosterol therapy in combination with statins, fibrates, ezetimibe, niacin, bile acid resins, omega-3 fatty acids, and exercise.

\section{Statins}

Statins are widely used for their ability to inhibit cholesterol synthesis. Most studies have shown a significant added reduction in LDL cholesterol when phytosterols are combined with statin therapy. The effectiveness of combining phytosterols and statins is the likely result of targeting two distinct mechanisms: cholesterol absorption and cholesterol synthesis. As phytosterol intake can lead to a compensatory increase in whole-body cholesterol synthesis, ${ }^{101}$ statin use can overcome this. The first study to examine combined treatments used a low dose of phytosterols $(0.9 \mathrm{~g} / \mathrm{d})$ and showed no further reduction in LDL cholesterol with phytosterol addition. ${ }^{102}$ When consumed at higher doses (1.8-3.0 g/d), phytosterol addition to statin therapy lowered LDL cholesterol an additional 6\%-20\%. ${ }^{103-111}$ Because these studies were relatively short term lasting 4-12 weeks, De Jong et al ${ }^{112}$ examined the long-term effects of consuming $2.5 \mathrm{~g} / \mathrm{d}$ phytosterol (as stanol 
or sterol esters) with statin treatment lasting 85 weeks. After 45 weeks of treatment, both types of phytosterols lowered LDL cholesterol an average of $10.2 \%$, and after 85 weeks, the reduction was maintained at $10.9 \% .{ }^{112}$ Also noteworthy is the observation that combining phytosterols with statins is generally more effective in producing additional reductions in LDL cholesterol than doubling the statin dose, which yields further LDL cholesterol reductions of only $5 \%-7 \%$. ${ }^{113,114}$

\section{Fibrates}

Fibrates are primarily used to lower serum triglyceride and, as a secondary effect, raise HDL cholesterol, but they can have negative consequences in hypertriglyceridemic subjects by increasing LDL cholesterol. ${ }^{115}$ Phytosterol combination with fibrates has been examined as a therapeutic option to simultaneously lower triglyceride and LDL cholesterol levels, but results have been mixed. In one study, the addition of phytosterols to fibrate therapy lowered LDL cholesterol an additional $10 \%,{ }^{116}$ whereas combination therapy in another study showed no additional reductions. ${ }^{117}$ In an uncontrolled, serial treatment study, seven children with heterozygous familial hypercholesterolemia were treated in sequence with a low-cholesterol diet, followed by treatment with $2 \mathrm{~g} / \mathrm{d}$ phytosterols, then fibrates alone, and finally a phytosterol-fibrate half-dose combination. ${ }^{118}$ Compared to the low-cholesterol diet, both phytosterol and fibrate treatment separately lowered serum LDL cholesterol; the half-dose combination treatment produced equivalent reductions in LDL cholesterol to the full-dose fibrate treatment. ${ }^{118}$ Conversely, an apoE knockout mouse study demonstrated that a combination of phytosterols and fibrates negated the LDL cholesterol decreases observed with phytosterols alone, yielding serum values equivalent to controls. ${ }^{119}$ Thus, only 1 well-controlled study indicates that combining phytosterols with fibrate therapy is beneficial.

\section{Ezetimibe}

Ezetimibe decreases cholesterol absorption by inhibiting NPC1L1-dependent cholesterol absorption; ${ }^{120}$ thus, both ezetimibe and phytosterols function to inhibit cholesterol absorption, albeit by different mechanisms. However, combined therapy appears to offer no advantage over ezetimibe treatment alone. ${ }^{121}$

\section{Niacin}

Niacin is generally used to increase HDL cholesterol, although some lowering of LDL cholesterol can also occur. ${ }^{122}$ However, it appears that the combination of niacin and phytosterols has not been examined in clinical trials. The combination has been tested only in an apoE-deficient mouse model, in which phytosterols plus niacin had no advantage over phytosterols alone in lowering LDL cholesterol. ${ }^{119}$

\section{Bile acid resins (cholestyramine)}

Bile acid resins function by binding bile acids in the intestinal lumen, thus promoting their excretion from the body. In one study, adding phytosterols to cholestyramine treatment did not promote further lowering of LDL cholesterol during 3-month trial periods. ${ }^{123}$ In an uncontrolled sequential study to test a triple combination therapy, subjects were started on statins for 3 months, then phytosterols were added for 8 weeks, followed by the addition of cholestyramine for another 8 weeks. ${ }^{111}$ The addition of statins lowered LDL cholesterol by $39 \%$, phytosterols by an additional $13 \%$, and cholestyramine by an additional $15 \%$, suggesting that the triple therapy was most effective. ${ }^{111}$

\section{Omega-3 fatty acids}

Omega-3 fatty acid supplementation is known to lower serum triglycerides and to be anti-inflammatory. ${ }^{124}$ Combining phytosterols with diets rich in fish oil or high-oleic sunflower oil significantly lowered LDL cholesterol, but the fish oil and phytosterol combination also lowered serum triglycerides. ${ }^{125}$ In addition, the combination of fish oil and phytosterol significantly reduced serum markers of inflammation. ${ }^{126}$ Using a different approach, Jones and coworkers ${ }^{127,128}$ used phytosterols that were esterified to fatty acids derived from fish oil (high in 22:6n-3 and 20:5n-3) vs sunflower oil (high in 18:2n-6) or olive oil (high in 18:1n-9). Their results indicated that phytosterols esterified with fish oil fatty acids did not alter LDL cholesterol levels compared with the other phytosterol esters, but fasting and postprandial triglycerides levels were significantly decreased in the fish oil phytosterol treatment. Therefore, a combination of phytosterols and omega-3 fatty acids, whether consumed as fish oil or esterified directly to phytosterols, may be more cardioprotective because of their anti-inflammatory and triglyceride-lowering properties.

\section{Exercise}

Because exercise can increase HDL cholesterol concentrations and phytosterols do not typically affect HDL cholesterol, a study was conducted to examine the combined effect of phytosterols and exercise in previously sedentary hypercholesterolemic individuals. ${ }^{129}$ Although there was no sterol-by-exercise interaction, and thus no synergistic effect, phytosterol supplementation alone or in combination lowered LDL cholesterol without negating the positive 
HDL cholesterol increase and triglyceride lowering effect of the exercise program. In contrast, another study indicated that phytosterols offset exercise-induced increases in HDL cholesterol. ${ }^{130}$ Further study is needed to define interactive effects of phytosterol use and exercise.

\section{Safety considerations}

Concerns about the safety of phytosterol therapy stem from observations that increased consumption under normal metabolic conditions results in increased serum levels of phytosterols $^{131}$ and that patients with sitosterolemia are prone to premature atherosclerosis. ${ }^{132,133}$ Some studies have reported a correlation between serum phytosterol concentrations and cardiovascular risk, ${ }^{134-137}$ whereas other studies report no correlation ${ }^{138-141}$ or even an inverse correlation. ${ }^{142}$ A direct causal relationship between serum phytosterols and cardiovascular risk has not been reported. Caution should be used when attempting to associate serum phytosterols and cardiovascular risk, as there are confounding factors that must be considered in the analysis, such as baseline LDL cholesterol concentration ${ }^{139}$ and baseline cholesterol absorption efficiency. ${ }^{138}$ Helske et al ${ }^{143}$ recently observed a direct correlation between serum phytosterol concentration and their accumulation in stenotic aortic valves; however, there was no difference between the absolute concentration of phytosterols in serum or aortic valves in patients undergoing valve surgery vs controls. Other research indicates that phytosterols clearly do not accumulate in atherosclerotic plaque disproportionately to cholesterol. ${ }^{144,145}$ Regarding atherosclerotic risk, it was suggested that the small increase in absolute serum phytosterol concentration resulting from phytosterol therapy may have little impact on overall risk in view of the substantially greater decrease in plasma LDL cholesterol. $^{75}$

The impact of phytosterols on serum concentrations of fat-soluble vitamins and carotenoids has also been examined. Serum concentration values are often adjusted and expressed in relation to serum cholesterol (or cholesterol plus triglyceride) to account for changes in serum LDL concentration, as many of these compounds are associated with LDL particles. However, when assessing systemic vitamin or carotenoid status, lipid-standardized values may not reflect the total amount available for delivery to tissues. Although a meta-analysis of 10-15 trials per vitamin showed no effect on plasma vitamin A (retinol) or vitamin $\mathrm{D}$ concentrations, decreases in total serum $\alpha$ - and $\beta$-carotene, lycopene, and $\alpha$-tocopherol were regularly observed. ${ }^{75}$ Upon lipid standardization, only the decrease in serum $\beta$-carotene was significant. ${ }^{75}$ A monitoring program conducted by Unilever (manufacturer of phytosterols) resulted in a similar conclusion that phytosterol intake decreased serum concentration of lipophilic carotenoids. ${ }^{146}$ Increased consumption of fruits and vegetables concurrent with phytosterol therapy can prevent the decrease in lipid-standardized serum $\beta$-carotene, ${ }^{147,148}$ but only one study using metabolic kitchen-prepared meals has demonstrated that absolute serum vitamin and carotenoid concentrations can be maintained during phytosterol treatment when fatsoluble vitamins and carotenoids were consumed at levels formulated to meet Canadian Recommended Nutrient Intakes. ${ }^{149}$ When supplemental $\beta$-carotene and phytosterols were co-administered in croissants and muffins, total serum carotenoid and tocopherol concentrations were not lowered compared with controls, indicating that coadministration of $\beta$-carotene and phytosterols within the same food matrix may prevent phytosterol-induced serum reductions in free-living situations. ${ }^{150}$ The impact of very long-term phytosterol use on fat-soluble vitamins and carotenoids has not been assessed.

The safety and tolerability of phytosterols was determined in an 8-week study in 48 free-living men and women consuming phytosterols up to $9 \mathrm{~g} / \mathrm{d} .{ }^{151}$ No adverse effects were observed in several body systems, including musculoskeletal system, skin and appendages, central and peripheral nervous system, gastrointestinal system, extracardiac vascular, and respiratory system, and also there were no psychiatric effects. In a long-term study, men and women consuming $2.7 \mathrm{~g} / \mathrm{d}$ phytosterols for 1 year exhibited lower LDL cholesterol concentration with no change in the concentration of sex hormones, liver enzymes, albumin, glucose, or iron. ${ }^{152}$ Another study showed no effect of dietary phytosterols on the reproduction of rats through two generations. ${ }^{153}$

Parenteral nutrition-associated cholestasis in premature infants has been linked to phytosterols because much of the lipid in parenteral formulas is derived from phytosterol-rich soybean lipid. However, other factors have been implicated, including prematurity and poor development of the infant; in addition, the circulating phytosterol contents are over 25 times greater than that seen in normal human serum as a result of the phytosterols being directly injected into the circulation and thus provide little insight into the safety of dietary phytosterol consumption. ${ }^{154}$

Phytosterol toxicity has also been examined at the cellular level. Using in vitro assays, Baker et al ${ }^{155}$ tested the ability of phytosterols to bind to the uterine estrogen receptor or to alter the expression of estrogen-responsive genes. Phytosterols appeared to have no ability to bind receptors or to alter 
transcriptional activity, and also there was no any indication in rats of estrogenicity in vivo. Moreover, phytosterols (in either free or esterified form) appeared to exert no genotoxicity effects in several tests, including a bacterial mutation assay, a chromosome aberration assay, a bone marrow micronucleus assay, and a liver unscheduled DNA synthesis assay. ${ }^{156}$

The ability of phytosterols to become oxidized in a manner similar to cholesterol, by either high-temperature cooking or metabolically, has raised concerns about the biological impact of oxyphytosterols. ${ }^{157}$ To address their potential toxicity, oxyphytosterols were tested in a series of in vitro genotoxicity assays (bacterial mutation, chromosome aberration, and micronucleus), as well as a feeding study in rats. ${ }^{158}$ In each case, the oxyphytosterols exhibited no genotoxic effects. Ironically, oxyphytosterols appear to exert some beneficial biological effects. Oxyphytosterols were shown to decrease serum triglycerides, nonesterified fatty acids, and body fat in diabetic rodent models. ${ }^{159-161}$ The oxidized derivative of sitosterol, compared with nonoxidized sitosterol, may also have anti-inflammatory properties. ${ }^{162}$

\section{Pregnancy and breastfeeding}

In 1979, the phytosterol concentration in breast milk was reported to be directly correlated to plasma phytosterol concentration in lactating mothers consuming a normal diet, although the absolute plasma concentration was relatively low. ${ }^{163}$ No correlation was observed between breast milk phytosterol and infant plasma phytosterol concentrations. ${ }^{163}$ On the other hand, addition of phytosterols $(1.2 \mathrm{~g} / \mathrm{d})$ to the maternal diet postpartum resulted in decreased plasma cholesterol and increased plasma and breast milk phytosterols; infant plasma phytosterols increased as well, but to a lesser extent. ${ }^{164}$ Phytosterol administration $(1.8 \mathrm{~g} / \mathrm{d})$ during pregnancy did not significantly affect serum LDL cholesterol during the first or third trimester of pregnancy or even during 1 month postpartum; breast milk phytosterol concentration 1 month postpartum was not significantly affected by phytosterol therapy. ${ }^{165}$ Furthermore, maternal phytosterol therapy had no impact on the length of gestation, infants' growth, or serum $\beta$-carotene concentration at 1 and 6 months of age; the infants' cholesterol-adjusted serum $\beta$-carotene concentration was lower at 1 month of age, but this difference disappeared after 6 months. ${ }^{165}$ Phytosterol therapy has typically been avoided during pregnancy due to the lack of adequate research. Although these few studies suggest that phytosterols may be generally safe during pregnancy and lactation, clearly further research is needed to establish the efficacy of phytosterol therapy during pregnancy.

\section{Conclusions}

Phytosterols are widely-available nutraceutical compounds that provide an effective therapeutic strategy for lowering LDL cholesterol concentrations. Phytosterols are clinically safe and well-tolerated when consumed at recommended amounts that optimized cholesterol reduction. The US National Cholesterol Education Program recommends a phytosterol dose of $2 \mathrm{~g} / \mathrm{d}$ to enhance lowering of LDL cholesterol. The successful incorporation of phytosterols into a great number of food supplemental products demonstrates the feasibility of using them on a large scale. Phytosterols produce no adverse events, with the exception of modest effects on some lipid-soluble vitamins and carotenoids, which may be offset by an adequate dietary intake. As cotherapy with statin drugs, phytosterols provide additional LDL cholesterol lowering that is more effective than doubling the statin dose. Combining phytosterols with dietary omega-3 fatty acids (fish oil) is effective in lowering serum triglycerides and LDL cholesterol. More research is needed to determine the efficacy of phytosterol therapy in pregnant and lactating women. Together with other dietary, lifestyle, or pharmaceutical strategies, phytosterols are a useful tool for reducing LDL cholesterol concentrations. Emerging research also suggests other health benefits of phytosterols, including anti-inflammatory, ${ }^{166}$ anticancer, ${ }^{167}$ and immune regulatory effects. ${ }^{168}$

\section{Disclosure}

The authors report no conflicts of interest in this work.

\section{References}

1. Jimenez-Escrig A, Santos-Hidalgo AB, Saura-Calixto F. Common sources and estimated intake of plant sterols in the Spanish diet. J Agric Food Chem. 2006;54:3462-3471.

2. Phillips KM, Ruggio DM, Ashraf-Khorassani M. Phytosterol composition of nuts and seeds commonly consumed in the United States. J Agric Food Chem. 2005;53:9436-9445.

3. Weihrauch JL, Gardner JM. Sterol content of foods of plant origin. JAm Diet Assoc. 1978;73:39-47.

4. Normén L, Bryngelsson S, Johnsson M, et al. The phytosterol content of some cereal foods commonly consumed in Sweden and in the Netherlands. J Food Compost Anal. 2002;15:693-704.

5. Normén L, Johnsson M, Andersson H, van Gameren Y, Dutta P. Plant sterols in vegetables and fruits commonly consumed in Sweden. Eur J Nutr. 1999;38:84-89.

6. Normén AL, Brants HAM, Voorrips LE, Andersson HA, van den Brandt PA, Goldbohm RA. Plant sterol intakes and colorectal cancer risk in the Netherlands Cohort Study on Diet and Cancer. Am J Clin Nutr. 2001;74:141-148.

7. Valsta LM, Lemström A, Ovaskainen ML, et al. Estimation of plant sterol and cholesterol intake in Finland: quality of new values and their effect on intake. Br J Nutr. 2004;92:671-678.

8. Carr TP, Jesch ED. Food ingredients that reduce cholesterol absorption. Adv Food Nutr Res. 2006;51:165-204. 
9. Ostlund RE Jr, Racette SB, Okeke A, Stenson WF. Phytosterols that are naturally present in commercial corn oil significantly reduce cholesterol absorption in humans. Am J Clin Nutr. 2002;75:1000-1004.

10. Ostlund RE Jr, Racette SB, Stenson WF. Inhibition of cholesterol absorption by phytosterol-replete wheat germ compared with phytosterol-depleted wheat germ. Am J Clin Nutr. 2003;77:1385-1389.

11. Carr TP, Cornelison RM, Illston BJ, Stuefer-Powell CL, Gallaher DD. Plant sterols alter bile acid metabolism and reduce cholesterol absorption in hamsters fed a beef-based diet. Nutrition Research. 2002;22: $745-754$.

12. Carr TP, Gallaher DD, Yang C-H, Hassel CA. Increased intestinal contents viscosity reduces cholesterol absorption efficiency in hamsters fed hydroxypropyl methylcellulose. J Nutr. 1996;126:1463-1469.

13. Gylling H, Miettinen TA. The effect of cholesterol absorption inhibition on low density lipoprotein cholesterol level. Atherosclerosis. 1995;117:305-308.

14. Kesaniemi YA, Miettinen TA. Cholesterol absorption efficiency regulates plasma cholesterol level in the Finnish population. Eur J Clin Invest. 1987;17:391-395.

15. Rudel LL, Deckelman C, Wilson MD, Scobey M, Anderson R. Dietary cholesterol and downregulation of cholesterol $7 \alpha$-hydroxylase and cholesterol absorption in African green monkeys. J Clin Invest. 1994; 93:2463-2472.

16. Andersson SW, Skinner J, Ellegard L, et al. Intake of dietary plant sterols is inversely related to serum cholesterol concentration in men and women in the EPIC Norfolk population: a cross-sectional study. Eur J Clin Nutr. 2004;58:1378-1385.

17. Klingberg S, Ellegard L, Johansson I, et al. Inverse relation between dietary intake of naturally occurring plant sterols and serum cholesterol in northern Sweden. Am J Clin Nutr. 2008;87:993-1001.

18. Berger A, Jones PJH, Abumweis SS. Plant sterols: factors affecting their efficacy and safety as functional food ingredients. Lipids Health Dis. 2004;3:5

19. Ferrari RA, Esteves W, Mukherjee KD, Schulte E. Alteration of sterols and steryl esters in vegetable oils during industrial refining. J Agric Food Chem. 1997;45:4753-4757.

20. Nyström L, Paasonen A, Lampi AM, Piironen V. Total plant sterols, steryl ferulates and steryl glycosides in milling fractions of wheat and rye. J Cereal Sci. 2007;45:106-115

21. Vikström F, Holmbom B, Hamunen A. Sterols and triterpenyl alcohols in common pulpwoods and black liquor soaps. European Journal of Wood and Wood Products. 2005;63:303-308.

22. Verleyen T, Sosinska U, Ioannidou S, et al. Influence of the vegetable oil refining procees on free and esterified sterols. J Am Oil Chem Soc. 2002;79:947-953.

23. Phillips KM, Ruggio DM, Toivo JI, Swank MA, Simpkins AH. Free and esterified sterol composition of edible oils and fats. J Food Compost Anal. 2002;15:123-142.

24. World Health Organization. Cardiovascular diseases 2009. Available from: http://www.whoint/mediacentre/factsheets/fs317/en/. Accessed on March 1, 2010.

25. National Center for Health Statistics. Deaths: preliminary data for 2007. 2009 Available from: http://wwwcdegov/nchs/data/nvsr/nvsr58/ nvsr58_01pdf. Accessed on March 1, 2010.

26. British Heart Foundation. European cardiovascular disease statistics 2008. Available from: http://wwwheartstatsorg/temp/ ESspweb08spchapter1pdf. Accessed on March 1, 2010.

27. Lloyd-Jones D, Adams RJ, Brown TM, et al. Executive summary: heart sisease and stroke statistics - 2010 update: a report from the American Heart Association. Circulation. 2010;121:948-954.

28. Grundy SM, Cleeman JI, Merz CN, et al. Implications of recent clinical trials for the National Cholesterol Education Program Adult Treatment Panel III guidelines. Circulation. 2004;110:227-239.

29. National Institutes of Health. Third report of the National Cholesterol Education Program (NCEP) expert panel on detection, evaluation, and treatment of high blood cholesterol in adults (Adult Treatment Panel III): final report. Circulation. 2002;106:3143-3421.
30. Bays H. Statin safety: An overview and assessment of the data -2005. Am J Cardiol. 2006;97 Suppl:6C-26C.

31. Cannon $\mathrm{CP}$, Braunwald $\mathrm{E}, \mathrm{McCabe} \mathrm{CH}$, et al. Intensive versus moderate lipid lowering with statins after acute coronary syndromes. NEngl J Med. 2004;350:1495-1504.

32. Kastelein JJP, Akdim F, Stroes ESG, et al. Simvastatin with or without ezetimibe in familial hypercholesterolemia. $N$ Engl J Med. 2008; 358:1431-1443

33. McKenney JM, Davidson MH, Jacobson TA, Guyton JR. Final conclusions and recommendations of the National Lipid Association Statin Safety Assessment Task Force. Am J Cardiol. 2006;97:89C-94C.

34. Pandor A, Ara RM, Tumur I, et al. Ezetimibe monotherapy for cholesterol lowering in 2,722 people: systematic review and meta-analysis of randomized controlled trials. J Intern Med. 2009;265:568-580.

35. Florentin M, Liberopoulos EN, Mikhailidis DP, Elisaf MS. Fibrateassociated adverse effects beyond muscle and liver toxicity. Curr Pharm Des. 2008;14:574-587.

36. Maccubbin D, Koren MJ, Davidson M, et al. Flushing profile of extended-release niacin/laropiprant versus gradually titrated niacin extended-release in patients with dyslipidemia with and without ischemic cardiovascular disease. Am J Cardiol. 2009;104:74-81.

37. Lichtenstein AH, Appel LJ, Brands M, et al. Diet and lifestyle recommendations revision 2006: a scientific statement from the American Heart Association Nutrition Committee. Circulation. 2006;114:82-96.

38. World Health Organization. Preparation and use of food-based dietary guidelines. Report of a Joint FAO/WHO Consultation. Geneva. WHO Technical Report Series No 880; 1998.

39. Schoenheimer R. New contributions in sterol metabolism. Science. 1931;74:579-584.

40. Hofmann AF, Borgström B. The intraluminal phase of fat digestion in man: the lipid content of the micellar and oil phases of intestinal content obtained during fat digestion and absorption. $J$ Clin Invest. 1964;43:247-257.

41. Haikal Z, Play B, Landrier JF, et al. NPC1L1 and SR-BI are involved in intestinal cholesterol absorption from small-size lipid donors. Lipids. 2008;43:401-408.

42. Jesch ED, Carr TP. Sitosterol reduces micellar cholesterol solubility in model bile. Nutr Res. 2006;26:579-584.

43. Armstrong MJ, Carey MC. Thermodynamic and molecular determinants of sterol solubilities in bile salt micelles. J Lipid Res. 1987;28:1144-1155.

44. Heuman DM. Quantitative estimation of the hydrophilic-hydrophobic balance of mixed bile salt solutions. J Lipid Res. 1989;30:719-730.

45. Martínez I, Wallace G, Zhang C, et al. Diet-induced metabolic improvements in a hamster model of hypercholesterolemia are strongly linked to alterations of the gut microbiota. Appl Environ Microbiol. 2009; 75:4175-4184.

46. Christiansen L, Karjalainen M, Seppanen-Laakso T, Hiltunen R, Yliruusi J. Effect of beta-sitosterol on precipitation of cholesterol from non-aqueous and aqueous solutions. Int J Pharm. 2003;254:155-166.

47. Mel'nikov SM, Seijen ten Hoorn JW, Bertrand B. Can cholesterol absorption be reduced by phytosterols and phytostanols via a cocrystallization mechanism? Chem Phys Lipids. 2004;127:15-33.

48. Compassi S, Werder M, Boffelli D, Weber FE, Hauser H, Schulthess G. Cholesteryl ester absorption by small intestinal brush border membrane is protein-mediated. Biochemistry. 1995;34:16473-16482.

49. Ostlund RE Jr, McGill JB, Zeng CM, et al. Gastrointestinal absorption and plasma kinetics of soy $\Delta^{5}$-phytosterols and phytostanols in humans. Am J Physiol Endocrinol Metab. 2002;282:E911-E916.

50. Lütjohann D, Björkhem I, Beil UF, von Bergmann K. Sterol absorption and sterol balance in phytosterolemia evaluated by deuterium-labeled sterols: effect of sitostanol treatment. J Lipid Res. 1995;36:1763-1773.

51. Hui DY, Labonté ED, Howles PN. Development and physiological regulation of intestinal lipid absorption. III. Intestinal transporters and cholesterol absorption. Am J Physiol Gastrointest Liver Physiol. 2008;294:G839-G843. 
52. Fitzgerald ML, Mujawar Z, Tamehiro N. ABC transporters, atherosclerosis and inflammation. Atherosclerosis. 2010; Jan 21 [Epub ahead of print].

53. Altmann SW, Davis HR Jr, Zhu LJ, et al. Niemann-Pick C1 Like 1 protein is critical for intestinal cholesterol absorption. Science. 2004;303: 1201-1204.

54. Brown JM, Rudel LL, Yu L. NPC1L1 (Niemann-Pick C1-like 1) mediates sterol-specific unidirectional transport of non-esterified cholesterol in McArdle-RH7777 hepatoma cells. Biochem J. 2007;406: 273-283.

55. Yamanashi Y, Takada T, Suzuki H. Niemann-Pick C1-like 1 overexpression facilitates ezetimibe-sensitive cholesterol and betasitosterol uptake in CaCo-2 cells. J Pharmacol Exp Ther. 2007;320: 559-564.

56. Davis HR Jr, Zhu LJ, Hoos LM, et al. Niemann-Pick C1 Like 1 (NPC1L1) is the intestinal phytosterol and cholesterol transporter and a key modulator of whole-body cholesterol homeostasis. J Biol Chem. 2004;279:33586-33592.

57. Tang W, Ma Y, Jia L, Ioannou YA, Davies JP, Yu L. Genetic inactivation of NPC1L1 protects against sitosterolemia in mice lacking ABCG5/ ABCG8. J Lipid Res. 2009;50:293-300.

58. Nguyen D, Dhanasekaran P, Phillips MC, Lund-Katz S. Molecular mechanism of apolipoprotein $\mathrm{E}$ binding to lipoprotein particles. Biochemistry. 2009;48:3025-3032.

59. Salen G, Patel S, Batta AK. Sitosterolemia. Cardiovasc Drug Rev. 2002;20:255-270.

60. Wang HH, Patel SB, Carey MC, Wang DQH. Quantifying anomalous intestinal sterol uptake, lymphatic transport, and biliary secretion in Abcg8(-/-) mice. Hepatology. 2007;45:998-1006.

61. Wang N, Silver DL, Thiele C, Tall AR. ATP-binding cassette transporter A1 (ABCA1) functions as a cholesterol efflux regulatory protein. J Biol Chem. 2001;276:23742-23747.

62. Wang N, Lan D, Chen W, Matsuura F, Tall AR. ATP-binding cassette transporters G1 and G4 mediate cellular cholesterol efflux to high-density lipoproteins. Proc Natl Acad Sci U S A. 2004;101:9774-9779.

63. Field FJ, Born E, Mathur SN. LXR/RXR ligand activation enhances basolateral efflux of beta-sitosterol in CaCo-2 cells. J Lipid Res. 2004; 45:905-913.

64. Hovenkamp E, Lourbakos A, Duchateau GSMJE, Tareilus EW, Trautwein EA. Preferential efflux of phytosterols over cholesterol from macrophages. Lipids. 2007;42:1125-1132.

65. Jesch ED, Seo JM, Carr TP, Lee JY. Sitosterol reduces messenger RNA and protein expression levels of Niemann-Pick C1-like 1 in FHs 74 Int cells. Nutr Res. 2009;29:859-866.

66. Cantàfora A, Blotta I, Rivabene R, Pisciotta L, Bertolini S. Evaluation of RNA messengers involved in lipid trafficking of human intestinal cells by reverse-transcription polymerase chain reaction with competimer technology and microchip electrophoresis. Electrophoresis. 2003;24:3748-3754

67. Jain D, Ebine N, Jia X, et al. Corn fiber oil and sitostanol decrease cholesterol absorption independently of intestinal sterol transporters in hamsters. J Nutr Biochem. 2008;19:229-236.

68. Calpe-Berdiel L, Escolà-Gil JC, Ribas V, Navarro-Sastre A, GarcésGarcés J, Blanco-Vaca F. Changes in intestinal and liver global gene expression in response to a phytosterol-enriched diet. Atherosclerosis. 2005;181:75-85.

69. Brown AW, Hang J, Dussault PH, Carr TP. Plant sterol and stanol substrate specificity of pancreatic cholesterol esterase. J Nutr Biochem. Epub 2009 Jul 15.

70. Julien-David D, Ennahar S, Miesch M, et al. Effects of oxidation on the hydrolysis by cholesterol esterase of sitosteryl esters as compared to a cholesteryl ester. Steroids. 2009;74:832-836.

71. Field FJ, Mathur SN. beta-Sitosterol: esterification by intestinal acylcoenzyme A:cholesterol acyltransferase (ACAT) and its effect on cholesterol esterification. J Lipid Res. 1983;24:409-417.

72. Tavani DM, Nes WR, Billheimer JT. The sterol substrate specificity of acyl CoA:cholesterol acyltransferase from rat liver. J Lipid Res. 1982; 23:774-781.
73. Temel RE, Gebre AK, Parks JS, Rudel LL. Compared with acylCoA:cholesterol O-acyltransferase (ACAT) 1 and lecithin:cholesterol acyltransferase, ACAT2 displays the greatest capacity to differentiate cholesterol from sitosterol. J Biol Chem. 2003;278:47594-47601.

74. Ikeda I, Tanaka K, Sugano M, Vahouny GV, Gallo LL. Inhibition of cholesterol absorption in rats by plant sterols. J Lipid Res. 1988;29:1573-1582.

75. Katan MB, Grundy SM, Jones P, Law M, Miettinen T, Paoletti R. Efficacy and safety of plant stanols and sterols in the management of blood cholesterol levels. Mayo Clin Proc. 2003;78:965-978.

76. Law M. Plant sterol and stanol margarines and health. Br Med J. 2000; 320:861-864.

77. Moruisi KG, Oosthuizen W, Opperman AM. Phytosterols/stanols lower cholesterol concentrations in familial hypercholesterolemic subjects: a systematic review with meta-analysis. J Am Coll Nutr. 2006 ; $25: 41-48$.

78. Wu T, Fu J, Yang Y, Zhang L, Han J. The effects of phytosterols/stanols on blood lipid profiles: a systematic review with meta-analysis. Asia Pac J Clin Nutr. 2009;18:179-186.

79. Naumann E, Plat J, Kester AD, Mensink RP. The baseline serum lipoprotein profile is related to plant stanol induced changes in serum lipoprotein cholesterol and triacylglycerol concentrations. J Am Coll Nutr. 2008;27:117-126.

80. Theuwissen E, Plat J, van der Kallen CJ, van Greevenbroek MM, Mensink RP. Plant stanol supplementation decreases serum triacylglycerols in subjects with overt hypertriglyceridemia. Lipids. 2009; 44:1131-1140.

81. Demonty I, Ras RT, van der Knaap HC, et al. Continuous dose-response relationship of the LDL-cholesterol-lowering effect of phytosterol intake. J Nutr. 2009; 139:271-284.

82. Doornbos AME, Meynen EM, Duchateau GSMJE, van der Knaap HCM, Trautwein EA. Intake occasion affects the serum cholesterol lowering of a plant sterol-enriched single-dose yoghurt drink in mildly hypercholesterolaemic subjects. Eur J Clin Nutr. 2006;60:325-333.

83. Matvienko OA, Lewis DS, Swanson M, et al. A single daily dose of soybean phytosterols in ground beef decreases serum total cholesterol and LDL cholesterol in young, mildly hypercholesterolemic men. Am J Clin Nutr. 2002;76:57-64.

84. Plat J, van Onselen EN, van Heugten MM, Mensink RP. Effects on serum lipids, lipoproteins and fat soluble antioxidant concentrations of consumption frequency of margarines and shortenings enriched with plant stanol esters. Eur J Clin Nutr. 2000;54:671-677.

85. AbuMweis SS, Vanstone CA, Ebine N, et al. Intake of a single morning dose of standard and novel plant sterol preparations for 4 weeks does not dramatically affect plasma lipid concentrations in humans. J Nutr. 2006;136:1012-1016.

86. Lau VWY, Journoud M, Jones PJH. Plant sterols are efficacious in lowering plasma LDL and non-HDL cholesterol in hypercholesterolemic type 2 diabetic and nondiabetic persons. Am J Clin Nutr. 2005;81 1351-1358.

87. AbuMweis SS, Vanstone CA, Lichtenstein AH, Jones PJH. Plant sterol consumption frequency affects plasma lipid levels and cholesterol kinetics in humans. Eur J Clin Nutr. 2009;63:747-755.

88. Allen RR, Carson L, Kwik-Uribe C, Evans EM, Erdman JW Jr. Daily consumption of a dark chocolate containing flavanols and added sterol esters affects cardiovascular risk factors in a normotensive population with elevated cholesterol. J Nutr. 2008;138:725-731.

89. Miettinen TA, Vuoristo M, Nissinen M, Jarvinen HJ, Gylling H. Serum, biliary, and fecal cholesterol and plant sterols in colectomized patients before and during consumption of stanol ester margarine. Am J Clin Nutr. 2000;71:1095-1102.

90. Judd JT, Baer DJ, Chen SC, et al. Plant sterol esters lower plasma lipids and most carotenoids in mildly hypercholesterolemic adults. Lipids. 2002;37:33-42.

91. Maki KC, Davidson MH, Umporowicz DM, et al. Lipid responses to plantsterol-enriched reduced-fat spreads incorporated into a National Cholesterol Education Program Step I diet. Am J Clin Nutr. 2001;74:33-43. 
92. Weststrate JA, Meijer GW. Plant sterol-enriched margarines and reduction of plasma total- and LDL-cholesterol concentrations in normocholesterolaemic and mildly hypercholesterolaemic subjects. Eur J Clin Nutr. 1998;52:334-343.

93. Chen SC, Judd JT, Kramer M, Meijer GW, Clevidence BA, Baer DJ. Phytosterol intake and dietary fat reduction are independent and additive in their ability to reduce plasma LDL cholesterol. Lipids. 2009:44:273-281.

94. AbuMweis SS, Barake R, Jones PJ. Plant sterols/stanols as cholesterol lowering agents: a meta-analysis of randomized controlled trials. Food Nutr Res. 2008;52.

95. Clifton PM, Noakes M, Sullivan D, et al. Cholesterol-lowering effects of plant sterol esters differ in milk, yoghurt, bread and cereal. Eur J Clin Nutr. 2004;58:503-509.

96. Goldberg AC, Ostlund RE Jr, Bateman JH, Schimmoeller L, McPherson TB, Spilburg CA. Effect of plant stanol tablets on lowdensity lipoprotein cholesterol lowering in patients on statin drugs. Am J Cardiol. 2006;97:376-379.

97. McPherson TB, Ostlund RE, Goldberg AC, Bateman JH, Schimmoeller L, Spilburg CA. Phytostanol tablets reduce human LDL-cholesterol. J Pharm Pharmacol. 2005;57:889-896.

98. Acuff R, Cai D, Dong Z-P, Bell D. The lipid lowering effect of plant sterol ester capsules in hypercholesterolemic subjects. Lipids Health Dis. 2007;6:11.

99. Earnest CP, Mikus CR, Lemieux I, Arsenault BJ, Church TS. Examination of encapsulated phytosterol ester supplementation on lipid indices associated with cardiovascular disease. Nutrition. 2007;23:625-633.

100. Carr TP, Stanek Krogstrand KL, Schlegel VL, Fernandez ML. Stearate-enriched plant sterol esters lower serum LDL cholesterol concentration in normo- and hypercholesterolemic adults. $J$ Nutr. 2009;139:1445-1450.

101. Calpe-Berdiel L, Escolà-Gil JC, Blanco-Vaca F. New insights into the molecular actions of plant sterols and stanols in cholesterol metabolism. Atherosclerosis. 2009;203:18-31.

102. Vanhanen H. Cholesterol malabsorption caused by sitostanol ester feeding and neomycin in pravastatin-treated hypercholesterolaemic patients. Eur J Clin Pharmacol. 1994;47:169-176.

103. Blair SN, Capuzzi DM, Gottlieb SO, Nguyen T, Morgan JM, Cater NB. Incremental reduction of serum total cholesterol and low-density lipoprotein cholesterol with the addition of plant stanol ester-containing spread to statin therapy. Am J Cardiol. 2000;86:46-52.

104. De Jong A, Plat J, Bast A, Godschalk RW, Basu S, Mensink RP. Effects of plant sterol and stanol ester consumption on lipid metabolism, antioxidant status and markers of oxidative stress, endothelial function and low-grade inflammation in patients on current statin treatment. Eur J Clin Nutr. 2008;62:263-273.

105. Goldberg AC, Ostlund RE, Bateman JH, Schimmoeller L, McPherson TB, Spilburg CA. Effect of plant stanol tablets on lowdensity lipoprotein cholesterol lowering in patients on statin drugs. Am J Cardiol. 2006;97:376-379.

106. Gylling H, Miettinen TA. Effects of inhibiting cholesterol absorption and synthesis on cholesterol and lipoprotein metabolism in hypercholesterolemic non-insulin-dependent diabetic men. J Lipid Res. 1996;37:1776-1785.

107. Gylling H, Radhakrishnan R, Miettinen TA. Reduction of serum cholesterol in postmenopausal women with previous myocardial infarction and cholesterol malabsorption induced by dietary sitostanol ester margarine: women and dietary sitostanol. Circulation. 1997;96:4226-4231.

108. Neil HAW, Meijer GW, Roe LS. Randomised controlled trial of use by hypercholesterolaemic patients of a vegetable oil sterol-enriched fat spread. Atherosclerosis. 2001;156:329-337.

109. O'Neill FH, Brynes A, Mandeno R, et al. Comparison of the effects of dietary plant sterol and stanol esters on lipid metabolism. Nutr Metab Cariovasc Dis. 2004;14:133-142.
110. Vuorio AF, Gylling H, Turtola H, Kontula K, Ketonen P, Miettinen TA. Stanol ester margarine alone and with simvastatin lowers serum cholesterol in families with familial hypercholesterolemia caused by the FH-North Karelia mutation. Arterioscler Thromb Vasc Biol. 2000;20:500-506.

111. Gylling H, Miettinen T. LDL cholesterol lowering by bile acid malabsorption during inhibited synthesis and absorption of cholesterol in hypercholesterolemic coronary subjects. Nutr Metab Cardiovasc Dis. 2002;12:19-23.

112. De Jong A, Plat J, Lütjohann D, Mensink RP. Effects of long-term plant sterol or stanol ester consumption on lipid and lipoprotein metabolism in subjects on statin treatment. Br J Nutr. 2008;100:937-941.

113. Dujovne CA. New lipid lowering drugs and new effects of old drugs. Curr Opin Lipidol. 1997;8:362-368.

114. Jacobson TA. Improving health outcomes without increasing costs: maximizing the full potential of lipid reduction therapy in the primary and secondary prevention of coronary heart disease. Curr Opin Lipidol. 1997;8:369-374.

115. Chapman MJ. Fibrates in 2003: therapeutic action in atherogenic dyslipidaemia and future perspectives. Atherosclerosis. 2003;171:1-13.

116. Nigon F, Serfaty-Lacrosnière C, Beucler I, et al. Plant sterol-enriched margarine lowers plasma LDL in hyperlipidemic subjects with low cholesterol intake: effect of fibrate treatment. Clin Chem Lab Med. 2001;39:634-640.

117. Grundy SM, Mok HYI. Colestipol, clofibrate, and phytosterols in combined therapy of hyperlipidemia. J Lab Clin Med. 1977;89:354-366.

118. Becker M, Staab D, Von Bergman K. Long-term treatment of severe familial hypercholesterolemia in children: effect of sitosterol and bezafibrate. Pediatrics. 1992;89:138-142.

119. Yeganeh B, Moshtaghi-Kashanian GR, Declercq V, Moghadasian MH. Combination of dietary phytosterols plus niacin or fenofibrate: effects on lipid profile and atherosclerosis in apo E-KO mice. J Nutr Biochem. 2005; 16:222-228.

120. Garcia-Calvo M, Lisnock J, Bull HG, et al. The target of ezetimibe is Niemann-Pick C1-Like 1 (NPC1L1). Proc NatlAcad Sci USA. 2005;102: 8132-8137.

121. Jakulj L, Trip MD, Sudhop T, Von Bergmann K, Kastelein JJ, Vissers MN. Inhibition of cholesterol absorption by the combination of dietary plant sterols and ezetimibe: effects on plasma lipid levels. J Lipid Res. 2005;46:2692-2698.

122. Birjmohun RS, Hutten BA, Kastelein JJP, Stroes ESG. Efficacy and safety of high-density lipoprotein cholesterol-increasing compounds: a meta-analysis of randomized controlled trials. $J$ Am Coll Cardiol. 2005;45:185-197.

123. Denke MA. Lack of efficacy of low-dose sitostanol therapy as an adjunct to a cholesterol-lowering diet in men with moderate hypercholesterolemia. Am J Clin Nutr. 1995;61:392-396.

124. Balk EM, Lichtenstein AH, Chung M, Kupelnick B, Chew P, Lau J. Effects of omega-3 fatty acids on serum markers of cardiovascular disease risk: a systematic review. Atherosclerosis. 2006;189:19-30.

125. Micallef MA, Garg ML. The lipid-lowering effects of phytosterols and (n-3) polyunsaturated fatty acids are synergistic and complementary in hyperlipidemic men and women. J Nutr. 2008;138:1086-1090.

126. Micallef MA, Garg ML. Anti-inflammatory and cardioprotective effects of n-3 polyunsaturated fatty acids and plant sterols in hyperlipidemic individuals. Atherosclerosis. 2009;204:476-482.

127. Demonty I, Chan YM, Pelled D, Jones PJH. Fish-oil esters of plant sterols improve the lipid profile of dyslipidemic subjects more than do fish-oil or sunflower oil esters of plant sterols. Am J Clin Nutr. 2006; 84:1534-1542.

128. Jones PJH, Demonty I, Chan YM, Herzog Y, Pelled D. Fish-oil esters of plant sterols differ from vegetable-oil sterol esters in triglycerides lowering, carotenoid bioavailability and impact on plasminogen activator inhibitor-1 (PAI-1) concentrations in hypercholesterolemic subjects. Lipids Health Dis. 2007;6:28. 
129. Varady KA, Ebine N, Vanstone CA, Parsons WE, Jones PJ. Plant sterols and endurance training combine to favorably alter plasma lipid profiles in previously sedentary hypercholesterolemic adults after $8 \mathrm{wk}$. Am J Clin Nutr. 2004;80:1159-1166.

130. Alhassan S, Reese KA, Mahurin J, et al. Blood lipid responses to plant stanol ester supplementation and aerobic exercise training. Metabolism. 2006;55:541-549.

131. Fransen HP, de Jong N, Wolfs M, et al. Customary use of plant sterol and plant stanol enriched margarine is associated with changes in serum plant sterol and stanol concentrations in humans. J Nutr. 2007;137:1301-1306.

132. Lütjohann D, von Bergmann K. Phytosterolaemia: diagnosis, characterization and therapeutical approaches. Ann Med. 1997;29:181-184.

133. Salen G, Tint GS, Shefer S. Increased sitosterol absorption is offset by rapid elimination to prevent accumulation in heterozygotes with sitosterolemia. Arterioscler Thromb. 1992;12:563-568.

134. Glueck CJ, Speirs J, Tracy T, Streicher P, Illig E, Vandegrift J. Relationships of serum plant sterols (phytosterols) and cholesterol in 595 hypercholesterolemic subjects, and familial aggregation of phytosterols, cholesterol, and premature coronary heart disease in hyperphytosterolemic probands and their first-degree relatives. Metabolism. 1991;40:842-848.

135. Sudhop T, Gottwald BM, von Bergmann K. Serum plant sterols as a potential risk factor for coronary heart disease. Metabolism. 2002; 51:1519-1521.

136. Rajaratnam RA, Gylling H, Miettinen TA. Independent association of serum squalene and noncholesterol sterols with coronary artery disease in postmenopausal women. J Am Coll Cardiol. 2000;35:1185-1191.

137. Assmann G, Cullen GP, Erbey J, Ramey DR, Kannenberg F, Schulte H. Plasma sitosterol elevations are associated with an increased incidence of coronary events in men: results of a nested case-control analysis of the Prospective Cardiovascular Munster (PROCAM) Study. Nutr Metab Cariovasc Dis. 2006;16:13-21.

138. Silbernagel G, Fauler G, Renner W, et al. The relationships of cholesterol metabolism and plasma plant sterols with the severity of coronary artery disease. J Lipid Res. 2009;50:334-341.

139. Windler E, Zyriax BC, Kuipers F, Linseisen J, Boeing H. Association of plasma phytosterol concentrations with incident coronary heart disease: data from the CORA study, a case-control study of coronary artery disease in women. Atherosclerosis. 2009;203:284-290.

140. Wilund KR, Yu L, Xu F, et al. No association between plasma levels of plant sterols and atherosclerosis in mice and men. Arterioscler Thromb Vasc Biol. 2004;24:2326-2332.

141. Pinedo S, Vissers MN, von Bergmann K, et al. Plasma levels of plant sterols and the risk of coronary artery disease: the prospective EPICNorfolk Population Study. J Lipid Res. 2007;48:139-144.

142. Fassbender K, Lütjohann D, Dik MG, et al. Moderately elevated plant sterol levels are associated with reduced cardiovascular risk - the LASA study. Atherosclerosis. 2008;196:283-288.

143. Helske S, Miettinen T, Gylling H, et al. Accumulation of cholesterol precursors and plant sterols in human stenotic aortic valves. J Lipid Res. 2008;49:1511-1518.

144. Miettinen TA, Railo M, Lepäntalo M, Gylling H. Plant sterols in serum and in atherosclerotic plaques of patients undergoing carotid endarterectomy. J Am Coll Cardiol. 2005;45:1794-1801.

145. Mellies MJ, Ishikawa TT, Glueck CJ, Bove K, Morrison J. Phytosterols in aortic tissue in adults and infants. $J$ Lab Clin Med. 1976;88:914-921.

146. Lea LJ, Hepburn PA. Safety evaluation of phytosterol-esters. Part 9: results of a European post-launch monitoring programme. Food Chem Toxicol. 2006;44:1213-1222.

147. Colgan HA, Floyd S, Noone EJ, Gibney MJ, Roche HM. Increased intake of fruit and vegetables and a low-fat diet, with and without low-fat plant sterol-enriched spread consumption: effects on plasma lipoprotein and carotenoid metabolism. J Hum Nutr Diet. 2004; 17:561-569.
148. Noakes M, Clifton P, Ntanios F, Shrapnel W, Record I, McInerney J. An increase in dietary carotenoids when consuming plant sterols or stanols is effective in maintaining plasma carotenoid concentrations. Am J Clin Nutr. 2002;75:79-86.

149. Raeini-Sarjaz M, Ntanios FY, Vanstone CA, Jones PJH. No changes in serum fat-soluble vitamin and carotenoid concentrations with the intake of plant sterol/stanol esters in the context of a controlled diet. Metabolism. 2002;51:652-656.

150. Quilez J, Rafecas M, Brufau G, et al. Bakery products enriched with phytosterol esters, $\alpha$-tocopherol and $\beta$-carotene decrease plasma LDLcholesterol and maintain plasma $\beta$-carotene concentrations in normocholesterolemic men and women. J Nutr. 2003;133:3103-3109.

151. Davidson MH, Maki KC, Umporowicz DM, et al. Safety and tolerability of esterified phytosterols administered in reduced-fat spread and salad dressing to healthy adult men and women. J Am Coll Nutr. 2001; 20:307-319.

152. Hendriks HFJ, Brink EJ, Meijer GW, Princen HMG, Ntanios FY. Safety of long-term consumption of plant sterol esters-enriched spread. Eur J Clin Nutr. 2003;57:681-692.

153. Waalkens-Berendsen DH, Wolterbeek AP, Wijnands MV, Richold M, Hepburn PA. Safety evaluation of phytosterol esters. Part 3. Twogeneration reproduction study in rats with phytosterol esters - a novel functional food. Food Chem Toxicol. 1999;37:683-696.

154. Carter BA, Taylor OA, Prendergast DR, et al. Stigmasterol, a soy lipidderived phytosterol, is an antagonist of the bile acid nuclear receptor FXR. Pediatr Res. 2007;62:301-306.

155. Baker VA, Hepburn PA, Kennedy SJ, et al. Safety evaluation of phytosterol esters. Part 1. Assessment of oestrogenicity using a combination of in vivo and in vitro assays. Food Chem Toxicol. 1999;37: 13-22.

156. Wolfreys AM, Hepburn PA. Safety evaluation of phytosterol esters. Part 7. Assessment of mutagenic activity of phytosterols, phytosterol esters and the cholesterol derivative, 4-cholesten-3-one. Food Chem Toxicol. 2002;40:461-470.

157. Hovenkamp E, Demonty I, Plat J, Lütjohann D, Mensink RP, Trautwein EA. Biological effects of oxidized phytosterols: a review of the current knowledge. Prog Lipid Res. 2008;47:37-49.

158. Lea LJ, Hepburn PA, Wolfreys AM, Baldrick P. Safety evaluation of phytosterol esters. Part 8 . Lack of genotoxicity and subchronic toxicity with phytosterol oxides. Food Chem Toxicol. 2004;42:771-783.

159. Ikeda I, Konno R, Shimizu T, et al. Campest-5-en-3-one, an oxidized derivative of campesterol, activates PPARalpha, promotes energy consumption and reduces visceral fat deposition in rats. Biochim Biophys Acta. 2006;1760:800-807.

160. Konno R, Kaneko Y, Suzuki K, Matsui Y. Effect of 5-Campestenone (24-methylcholest-5-en-3-one) on Zucker diabetic fatty rats as a type 2 diabetes mellitus model. Horm Metab Res. 2005;37:79-83.

161. Suzuki K, Tanaka M, Konno R, Kaneko Y. Effects of 5-campestenone (24-methylcholest-5-en-3-one) on the type 2 diabetes mellitus model animal C57BL/KsJ-db/db mice. Horm Metab Res. 2002; 34:121-126.

162. Kimura Y, Yasukawa K, Takido M, Akihisa T, Tamura T. Inhibitory effect of some oxygenated stigmastane-type sterols on 12-Otetradecanoylphorbol-13-acetate-induced inflammation in mice. Biol Pharm Bull. 1995;18:1617-1619.

163. Mellies MJ, Burton K, Larsen R, Fixler D, Glueck CJ. Cholesterol, phytosterols, and polyunsaturated/saturated fatty acid ratios during the first 12 months of lactation. Am J Clin Nutr. 1979;32:2383-2389.

164. Mellies MJ, Ishikawa TT, Gartside P, et al. Effects of varying maternal dietary cholesterol and phytosterol in lactating women and their infants. Am J Clin Nutr. 1978;31:1347-1354.

165. Laitinen K, Isolauri E, Kaipiainen L, Gylling H, Miettinen TA. Plant stanol ester spreads as components of a balanced diet for pregnant and breast-feeding women: evaluation of clinical safety. $\mathrm{Br} J \mathrm{Nutr}$. 2009;101:1797-1804. 
166. Loizou S, Lekakis I, Chrousos GP, Moutsatsou P. beta-Sitosterol exhibits anti-inflammatory activity in human aortic endothelial cells. Mol Nutr Food Res. 2009;54:1-8.

167. Woyengo TA, Ramprasath VR, Jones PJH. Anticancer effects of phytosterols. Eur J Clin Nutr. 2009;63:813-820.
168. Brüll F, Mensink RP, van den Hurk K, Duijvestijn A, Plat J. TLR2 activation is essential to induce a Th1 shift in human peripheral blood mononuclear cells by plant stanols and plant sterols. J Biol Chem. 2010;285:2951-2958.

\section{Publish your work in this journal}

Nutrition and Dietary Supplements is an international, peer-reviewed, open access journal focusing on research into nutritional requirements in health and disease, impact on metabolism and the identification and optimal use of dietary strategies and supplements necessary for normal growth and development. The journal welcomes papers covering original research, basic science, clinical \& epidemiological studies, reviews and evaluations, guidelines, expert opinion and commentary, case reports and extended reports. The manuscript management system is completely online and includes a very quick and fair peer-review system, which is all easy to use.

Submit your manuscript here: http://www.dovepress.com/nutrition-and-dietary-supplements-journal 